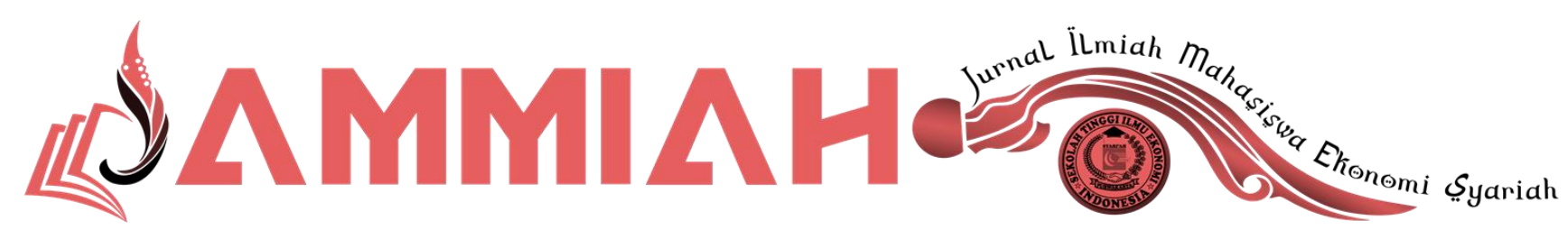

Volume 1 Nomor 1, Maret 2020

DOI: https://doi.org/10.37726/

\title{
Strategi Bauran Pemasaran (Marketing Mix) Dalam Meningkatkan Omzet Penjualan Di PT. Sanbe Divisi Infus Area Purwakarta
}

\author{
Mochammad Hamdan \\ PT. Sanbe Divisi Infus Area Purwakarta \\ hm244726@gmail.com
}

\begin{abstract}
ABSTRAK
Dalam dunia usaha sekarang ini tingkat persaingan antara industri-industri bisnis semakin tajam, tak terkecuali dengan perusahaan-perusahaan yang berada di Indonesia. Dengan semakin majunya teknologi pada era globalisasi ini, setiap perusahaan berusaha untuk selalu meningkatkan kualitas produksi maupun manajemen pemasaran dengan tujuan memaksimalkan keuntungan-keuntungan sesuai target yang diinginkan oleh setiap perusahaan. Persaingan yang semakin ketat dalam dunia bisnis telah merambah ke semua sektor usaha (bisnis), sehingga kompetisi yang ada antara perusahaan semakin ketat. Fokus penelitian ini adalah untuk mengetahui Strategi Bauran Pemasaran (Marketing Mix) Dalam Meningkatkan Omzet Penjualan Di PT. Sanbe Divisi Infus Area Purwakarta. Hasil analisis menunjukkan bahwa Strategi Bauran Pemasaran (Marketing Mix) Dalam Meningkatkan Omzet Penjualan Di PT. Sanbe Divisi Infus Area Purwakarta tidak terlepas dari konsep Bauran Pemasaran yaitu : Produk, dimana PT. Sanbe Divisi infus Area Purwakarta unggul dalam kemasan karena menggunakan kemasan softbag. Kemudian dari Harga, Harga produk infusan PT. Sanbe Divisi Infus Area Purwakarta mampu mengikuti trend market sehingga mampu bersaing di area coverage. Kemudian dari Distribusi, Responsif distribusi dari PT. Sanbe Divisi Infus Area Purwakarta terhadap demand/permintaan sangat stabil. Kemudian dari Promosi, Melalui Personal Selling oleh Medical Representative terhadap Rumah Sakit area Purwakarta secara
\end{abstract}

JAMMIAH (Jurnal Ilmiah Mahasiswa Ekonomi Syariah), Volume 1, Nomor 1, Maret 2021

http://journal.sties-purwakarta.ac.id/index.php/jammiah/

ISSN: xxxx-xxxx (Media Online) xxxx-xxxx (Media Cetak) 
maintenance, sehingga omzet penjualan dari produk infusan PT. Sanbe Divisi Infus Area Purwakarta selalu stabil bahkan cenderung meningkat dari setiap bulannya. Kata kunci : Bauran Pemasaran, Omzet penjualan.

\section{ABSTRACT}

In today's business world, the level of competition between business industries is getting sharper, no exception with companies in Indonesia. With the advancement of technology in this era of globalization, every company strives to always improve the quality of production and marketing management with the aim of maximizing profits-profits according to the target desired by each company. Increasingly tight competition in the business world has penetrated into all business sectors (businesses), so that the competition between companies is getting tighter. The focus of this research is to find out the Marketing Mix Strategy in increasing sales turnover in PT. Sanbe Purwakarta Area Infusion Division. The results of the analysis showed that the Marketing Mix Strategy In Increasing Sales Turnover In PT. Sanbe Purwakarta Area Infusion Division is inseparable from the concept of Marketing Mix namely: Products, where PT. Sanbe Purwakarta Area Infusion Division excels in packaging because it uses softbag packaging. Then from the Price, The price of infusion products PT. Sanbe Purwakarta Area Infusion Division is able to follow the market trend so that it can compete in the coverage area. Then from Distribution, Responsive distribution from PT. Sanbe Purwakarta Area Infusion Division to demand is verystable. Then from the Promotion, Through Personal Selling by the Medical Representative to the Hospital Purwakarta area on a maintenance basis,so that the sales turnover of infusion products PT. Sanbe Purwakarta Area Infusion Division is always stable and even tends to increase from every month.

Keywords: Marketing Mix, Medical Representative, Turnover.

\section{PENDAHULUAN}

Perkembangan ilmu pengetahuan dan teknologi yang pesat sekarang ini, membuat kita untuk lebih membuka diri dalam menerima perubahan-perubahan yang terjadi akibat kemajuan dan perkembangan tersebut ${ }^{1}$. Dalam dunia usaha sekarang ini tingkat persaingan antara industri-industri bisnis semakin tajam, tak terkecuali dengan perusahaan-perusahaan yang berada di Indonesia. Dengan semakin majunya teknologi pada era globalisasi ini, setiap perusahaan berusaha untuk selalu meningkatkan kualitas produksi maupun manajemen pemasaran dengan tujuan memaksimalkan keuntungankeuntungan sesuai target yang

${ }^{1}$ Ngafifi, Muhamad. Kemajuan Teknologi Dan Pola Hidup Manusia Dalam Perspektif Sosial Budaya. Jurnal Pembangunan Pendidikan: Fondasi Dan Aplikasi, 2014, 2.1.

JAMMIAH (Jurnal Ilmiah Mahasiswa Ekonomi Syariah), Volume 1, Nomor 1, Maret 2021 
diinginkan oleh setiap perusahaan. Persaingan yang semakin ketat dalam dunia bisnis telah merambah ke semua sektor usaha (bisnis), sehingga kompetisi yang ada antara perusahaan semakin ketat ${ }^{2}$.

Penelitian tentang Strategi Bauran Pemasaran (Marketing Mix) dalam meningkatkan Omzet Penjualan sudah banyak dilakukan oleh peneliti sebelumnya seperti yang dilakukan oleh Rina Rachmawati ${ }^{3}$. Penelitian ini bertujuan untuk mengetahui Peranan Strategi Bauran Pemasaran (Marketing Mix) Terhadap Omzet Penjualan. Hasil penelitian ini menunjukkan bahwa salah satu bentuk strategi pemasaran yang mampu mendukung dalam memasarkan produk makanan untuk menciptakan loyalitas konsumen adalah penggunaan strategi marketing mix (bauran pemasaran) yang meliputi product, price, promotion, dan physical evidence atau place. Penelitian ini hanya mengkaji Strategi Bauran Pemasaran (Marketing Mix) Terhadap Omzet Penjualan makanan saja. Selanjutnya penelitian dilakukan oleh Geraldy Tambajong4. Hasil penelitian menunjukkan bahwa bauran pemasaran dalam hal ini variabel produk dan harga berpengaruh signifikan terhadap volume penjualan. Sedangkan variabel tempat dan promosi tidak berpengaruh signifikan terhadap volume penjualan Sepeda Motor Karena itu perusahaan harus bisa mengembangkan strategi dari segi tempat dan promosi antara lain harus bisa menambah dealer Sepeda Motor Yamaha karena lokasi PT. Sarana Niaga Megah Kerta Manado yang bertempat di Jl. Sudirman belumlah strategis. Sedangkan promosi harus lebih ditingkatkan lagi agar volume penjualan sepeda motor bertambah pada PT. Sarana Niaga Megah Kerta Manado. Penelitian ini juga hanya berfokus pada penjualan sepeda motor tidak penjualan secara sistemik atau keseluruhan dan bukan penjualan pada alat kesehatan atau sediaan farmasi lainnya.

Penelitian-penelitian sebelumnya banyak mengkaji atau meneliti tentang strategi bauran pemasaran (marketing mix) terhadap penjualan barang dan makanan saja tidak dengan Perbekalan alat kesehatan atau sediaan farmasi berupa infusan.

Penelitian ini mengkaji lebih berbeda terkait strategi Bauran Pemasaran (Marketing Mix) yang berpengaruh terhadap omzet penjualan khususnya Sediaan Farmasi berupa Infusan.

${ }^{2}$ Hartono, Hendry; Hutomo, Karyana; Mayangsari, Marshelia. Pengaruh Strategi Pemasaran Terhadap Peningkatan Penjualan Pada Perusahaan" Dengan Menetapkan Alumni Dan Mahasiswa Universitas Bina Nusantara Sebagai Objek Penelitian. Binus Business Review, 2012, 3.2: 882-897.

${ }^{3}$ Rachmawati, Rina. Peranan Bauran Pemasaran (Marketing Mix) Terhadap Peningkatan Penjualan (Sebuah Kajian Terhadap Bisnis Restoran). Jurnal Kompetensi Teknik, 2011, 2.2.

${ }^{4}$ Tambajong, Geraldy. Bauran Pemasaran Pengaruhnya Terhadap Penjualan Sepeda Motor Yamaha Di PT. Sarana Niaga Megah Kerta Manado. Jurnal EMBA: Jurnal Riset Ekonomi, Manajemen, Bisnis Dan Akuntansi, 2013, 1.3.

JAMMIAH (Jurnal Ilmiah Mahasiswa Ekonomi Syariah), Volume 1, Nomor 1, Maret 2021 
Fokus penelitian ini adalah untuk mengetahui Strategi Bauran Pemasaran (Marketing Mix) dalam meningkatkan Omzet Penjualan Di PT. Sanbe Divisi Infus Area Purwakarta.

\section{TINJAUAN PUSTAKA}

Penelitian tentang Peranan Strategi Bauran Pemasaran (Marketing Mix) Dalam meningkatkan Omzet Penjualan sudah banyak dilakukan oleh peneliti sebelumnya seperti yang dilakukan oleh Muhammad Irfan Nasution, Muhammad Andi Prayogi, Satria Mirsya Affandy Nasutio ${ }^{5}$. Tujuan dari penelitian ini adalah untuk menganalisis pengaruh dari bauran pemasaran terhadap kinerja penjualan secara parsial dan simultan. Variabel bauran pemasaran adalah produk, harga, promosi dan tempat. Penelitian kuantitatif adalah pendekatan penelitian ini. Contoh Jumlah penelitian ini 71 responden. Teknik pengambilan sampel menggunakan sample pengambilan, sampel secara acak. Selanjutnya teknik analisis datanya adalah regresi linier berganda. Industri mikro pembuat sepatu di Kecamatan Medan Denai-Indonesia menjadi sasaran dalam penelitian ini.

Selanjutnya penelitian ini dilakukan oleh Andi Faisal Suddin ${ }^{6}$. Penelitian ini bertujuan untuk menganalisis pengaruh bauran pemasaran meliputi produk, harga dan distribusi hingga volume penjualan produk broiler di beberapa pasar tradisional di Indonesia kota Makassar (pasar sentral, pasar terong, pasar pa'baeng-baeng, pasar panampu dan daya market). Desain penelitian menggunakan studi cross sectional dengan jumlah sampel 100 orang.

Selanjutnya penelitian ini dilakukan oleh Galih Kusnawan, Purwohadi Wijoyo7. Hasil analisis menunjukan bahwa volume penjualan sayuran hidroponik mengalami kenaikan untuk tiap tahunnya. Berdasarkan analisis regresi berganda, efektivitas volume penjualan dipengaruhi oleh strategi bauran pemasaran (Marketing Mix) yang terdiri dari: Produk, Harga, Promosi, dan Distribusi (Place). Perbedaan dengan penelitian yang dilakukan sekarang adalah pembahasan variable yang berhubungan dengan penerapan strategi bauran pemasaran (Marketing Mix) terhadap omzet penjualan Infusan PT. Sanbe Infus area Purwakarta.

${ }^{5}$ Nasution, Muhammad Irfan; Prayogi, Muhammad Andi; Nasution, Satria Mirsya Affandy. Analisis Pengaruh Bauran Pemasaran Terhadap Volume Penjualan. Jurnal Riset Sains Manajemen, 2017, 1.1: 1-12.

${ }^{6}$ Suddin, Andi Faisal. Pengaruh Bauran Pemasaran Terhadap Volume Penjualan Produk Ayam Pedaging Di Kota Makassar. Jurnal Ilmu Dan Industri Peternakan, 2013, 1.1.

${ }^{7}$ Kusnawan, Galih; Wijoyo, Purwohadi. Pengaruh Strategi Bauran Pemasaran (Marketing Mix) Terhadap Efektivitas Volume Penjualan Sayuran Hidroponik. Agricultural Socio-Economics Journal, 2008, 8.2: 97.

JAMMIAH (Jurnal Ilmiah Mahasiswa Ekonomi Syariah), Volume 1, Nomor 1, Maret 2021 


\section{HASIL DAN PEMBAHASAN}

\section{A.Strategi Bauran Pemasaran (Marketing Mix) Dalam Meningkatkan Omzet Penjualan Di PT. Sanbe Divisi Infus Area Purwakarta}

PT. Sanbe Divisi Infus area Purwakarta yang beralamat di Jl. Perumahan Bukit Panorama Indah Blok A 11 No. 12 Purwakarta yang bergerak dalam bidang Marketing Farmasi menerapkan strategi bauran pemasaran (Marketing Mix) yang terdiri dari Produk, Harga, Promosi, dan Distribusi.

\section{Product (Produk)}

Berikut di bawah ini merupakan daftar Produk dari PT Sanbe divisi Infus Area Purwakarta yaitu :

Tabel 3.1

Daftar Produk dari PT. Sanbe Divisi Infus Area Purwakarta

\begin{tabular}{ll}
\hline No & \multicolumn{1}{c}{ Nama Produk } \\
\hline 1 & Ringer Lactate \\
\hline 2 & Ringer Dextrose \\
\hline 3 & Dextrose + Nacl 0,9 \\
\hline 4 & Dextrose 5\% 100ml \\
\hline 5 & Dextrose 5\% 250ml \\
\hline 6 & Ringer Acetate \\
\hline 7 & Ringer Lactate + Maltose 5\% \\
\hline 8 & Aa 5\% ( Bcaa 14,8 ), Electrolit \& Vitamin \\
\hline 9 & Aa 2,72\% (Bcaa 27,5\%), Sorbitol 5\% \\
\hline 10 & Dextrose 5\% + 0,225 Nacl \\
\hline 11 & Maltose 10\% \\
\hline 12 & Larutan Electrolit Na 38.5, Cl 38.5, Dextrosa 37.5 \\
\hline 13 & Larutan Electrolit Na 60, K 10, Cl 50, Laktat 20, Dextrosa 27 \\
\hline 14 & Larutan Electrolit Na 50, K 20, Cl 50, Laktat 20, Dextrosa 27 \\
\hline 15 & Larutan Electrolit Na 50, K 20, Cl 50, Laktat 20, Dextrosa 100 \\
\hline 16 & Ringer Acetate + Sorbitol 5\% \\
\hline 17 & Larutan Mengandung Lipid, Kemasan100 Ml - Lipomed 20\% Mct/Lct \\
\hline 18 & Larutan Mengandung Lipid , Kemasan 250 Ml - Lipomed 20\% Mct/Lct \\
\hline 19 & Dextrose 5\% + 0,45 Nacl \\
\hline
\end{tabular}

Adapun keunggulan dari Produk PT. Sanbe Divisi Infus Area Purwakarta yaitu : Tabel 3.2

Keunggulan Dari Produk PT. Sanbe Divisi Infus Area Purwakarta

JAMMIAH (Jurnal Ilmiah Mahasiswa Ekonomi Syariah), Volume 1, Nomor 1, Maret 2021 


\begin{tabular}{ll}
\hline No & \multicolumn{1}{c}{ Kelebihan Produk } \\
\hline 1 & Penutup horizontal \\
\hline 2 & Kemasan softbag dapat efesien dalam penyimpanan \\
\hline 3 & Warna dan label yang merekat pada kemasan \\
\hline 4 & Tanda lingkaran merah yang menempel kuat pada kemasan \\
\hline 5 & Kemasan menggunakan bahan yang transparan \\
\hline 6 & Produk infus pertama di Indonesia yang menerapkan sterilisasi pada suhu \\
& $121^{0} \mathrm{C}$ selama 15 menit \\
\hline
\end{tabular}

\section{Price (Harga)}

Berikut di bawah ini merupakan daftar harga persatuan dari Produk PT. Sanbe divisi Infus Area Purwakarta yaitu :

Tabel 3.3

Daftar Harga Produk Dari PT. Sanbe Divisi Infus Area Purwakarta

\begin{tabular}{|c|c|c|}
\hline No & Nama Produk & Harga \\
\hline 1 & Ringer Lactate & Rp.17,950 \\
\hline 2 & Ringer Dextrose & Rp.18,900 \\
\hline 3 & Dextrose + Nacl 0,9 & Rp. 18,650 \\
\hline 4 & Dextrose $5 \% 100 \mathrm{ml}$ & Rp. 17,850 \\
\hline 5 & Dextrose $5 \% 250 \mathrm{ml}$ & Rp.17,750 \\
\hline 6 & Ringer Acetate & Rp. 20,500 \\
\hline 7 & Ringer Lactate + Maltose 5\% & Rp.91,600 \\
\hline 8 & Aa 5\% ( Bcaa 14,8 ), Electrolit \& Vitamin & Rp.20,000 \\
\hline 9 & Aa 2,72\% (Bcaa 27,5\%), Sorbitol 5\% & Rp. 21,550 \\
\hline 10 & Dextrose $5 \%+0,225 \mathrm{Nacl}$ & Rp.21,550 \\
\hline 11 & Maltose $10 \%$ & Rp.23,500 \\
\hline 12 & Larutan Electrolit $\mathrm{Na} 38.5, \mathrm{Cl} 38.5$, Dextrosa 37.5 & Rp.58.550 \\
\hline 13 & Larutan Electrolit Na 60, K 10, Cl 50, Laktat 20, Dextrosa 27 & Rp.72,900 \\
\hline 14 & Larutan Electrolit Na 50, K 20, Cl 50, Laktat 20, Dextrosa 27 & Rp. 112,000 \\
\hline 15 & Larutan Electrolit Na 50, K 20, Cl 50, Laktat 20, Dextrosa 100 & Rp.72,150 \\
\hline 16 & Ringer Acetate + Sorbitol 5\% & Rp. 127,600 \\
\hline 17 & $\begin{array}{l}\text { Larutan Mengandung Lipid, Kemasan100 Ml - Lipomed 20\% } \\
\text { Mct/Lct }\end{array}$ & Rp.231,950 \\
\hline 18 & $\begin{array}{l}\text { Larutan Mengandung Lipid, Kemasan } 250 \mathrm{Ml} \text { - Lipomed 20\% } \\
\text { Mct/Lct }\end{array}$ & Rp.18,750 \\
\hline 19 & Dextrose $5 \%+0,45 \mathrm{Nacl}$ & Rp.18,650 \\
\hline
\end{tabular}

JAMMIAH (Jurnal Ilmiah Mahasiswa Ekonomi Syariah), Volume 1, Nomor 1, Maret 2021 


\section{Place (Tempat/Distribusi)}

Berikut di bawah ini merupakan alur distribusi agar terjadinya omzet/penjualan dari Produk PT. Sanbe divisi Infus Area Purwakarta yaitu :

Bagan 3.1

Alur Distribusi Agar Terjadinya Omzet/Penjualan Dari Produk PT. Sanbe Divisi Infus Area Purwakarta

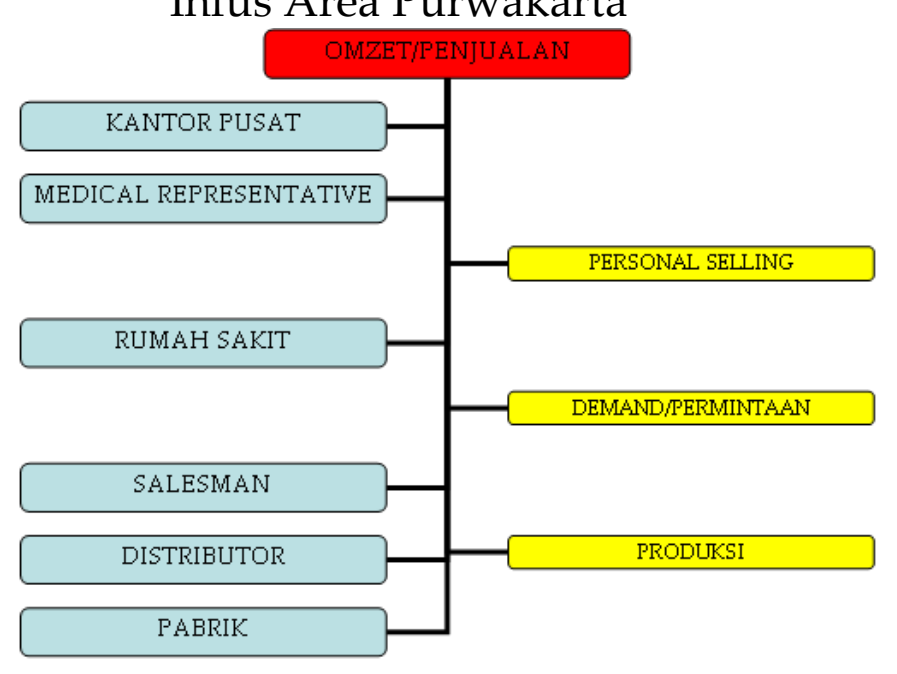

Dari gambar di atas dapat dilihat bahwa alur distribusi produk infusan PT. Sanbe Divisi Infus Area Purwakarta agar adanya omzet penjualan berawal dari peran kantor pusat yang memberikan tugas kepada Medical representative untuk kemudian melakukan personal selling dengan Rumah Sakit sehingga terjadinya demand/permintaan terhadap salesman dan distributor, kemudian pihak distributor melakukan follow up ke pabrik untuk koordinasi ketersediaan stok infusan sehingga dari demand/permintaan tersebut lah yang mengharuskan pabrik untuk selalu memproduksi infusan agar demand/permintaan Rumah sakit bisa terpenuhi dan omzet penjualan infusan terus meningkat.

\section{Promotion (Promosi)}

PT. Sanbe divisi Infus Area Purwakarta melakukan strategi promotion sebagai media perkenalan dan penjualan kepada konsumen khususnya Rumah Sakit, dalam kegiatan promosi tersebut PT. Sanbe Infus Area Purwakarta melalui Medical Representative melakukan promosi dengan cara personal selling (Penjualan tatap muka) Yakni usaha perusahaan dalam meningkatkan penjualan melalui perantara seorang Medical Representative yang kompeten di bidang penjualan dan pemasaran produk infus.

PT. Sanbe Divisi Infus Area Purwakarta memiliki Medical Representative sebagai tenaga penjual dalam bidang penjualan dan pemasaran produk infus yang sangat kompeten dengan berbagai macam style dan kemampuan yang di miliki, sehingga

JAMMIAH (Jurnal Ilmiah Mahasiswa Ekonomi Syariah), Volume 1, Nomor 1, Maret 2021 
dapat secara cepat menyesuaikan keadaan pasar, konsumen dan keadaan yang terjadi pada perusahaan. Sehingga secara cepat pula tenaga penjual tersebut mampu mengetahui seberapa besar minat dan keinginan calon konsumen akan produk perusahaan yang dia tawarkan.

Berikut di bawah ini merupakan Tabel Kegiatan promosi pada saat PKL di PT. Sanbe divisi Infus Area Purwakarta yaitu :

\section{Tabel 3.3}

Kegiatan Promosi Pada Saat PKL Di PT. Sanbe Divisi Infus Area Purwakarta

\begin{tabular}{|c|c|c|c|c|}
\hline Hari & Tanggal & Jam & Tempat & Kegiatan \\
\hline Kamis & $10 / 09 / 2020$ & $08.00 \mathrm{~s} / \mathrm{d}$ Selesai & RS Asri & Kunjungan / Detailing \\
\hline Jumat & $11 / 09 / 2020$ & $08.00 \mathrm{~s} / \mathrm{d}$ Selesai & RS Siloam & Kunjungan / Detailing \\
\hline Sabtu & $12 / 09 / 2020$ & $08.00 \mathrm{~s} / \mathrm{d} 12.00$ & Kantor & Laporan Mingguan \\
\hline Senin & $14 / 09 / 2020$ & $08.00 \mathrm{~s} / \mathrm{d}$ Selesai & Kantor & Pembuatan ReKun \\
\hline Selasa & $15 / 09 / 2020$ & $08.00 \mathrm{~s} / \mathrm{d}$ Selesai & RS Radjak & Kunjungan / Detailing \\
\hline Rabu & $16 / 09 / 2020$ & $08.00 \mathrm{~s} / \mathrm{d}$ Selesai & RS Ramahadi & Kunjungan / Detailing \\
\hline Kamis & $17 / 09 / 2020$ & $08.00 \mathrm{~s} / \mathrm{d}$ Selesai & RS Asri & Kunjungan / Detailing \\
\hline Jum'at & $18 / 09 / 2020$ & $08.00 \mathrm{~s} / \mathrm{d}$ Selesai & RS Siloam & Kunjungan / Detailing \\
\hline Sabtu & $19 / 09 / 2020$ & $08.00 \mathrm{~s} / \mathrm{d} 12.00$ & Kantor & Laporan Mingguan \\
\hline Senin & $21 / 09 / 2020$ & $08.00 \mathrm{~s} / \mathrm{d}$ Selesai & RS Radjak & Kunjungan / Detailing \\
\hline Selasa & $22 / 09 / 2020$ & $08.00 \mathrm{~s} / \mathrm{d}$ Selesai & RS Ramahadi & Kunjungan / Detailing \\
\hline Rabu & $23 / 09 / 2020$ & $08.00 \mathrm{~s} / \mathrm{d}$ Selesai & RS Asri & Kunjungan / Detailing \\
\hline Kamis & $24 / 09 / 2020$ & $08.00 \mathrm{~s} / \mathrm{d}$ Selesai & RS Ramahadi & Kunjungan / Detailing \\
\hline Jum'at & $25 / 09 / 2020$ & $08.00 \mathrm{~s} / \mathrm{d}$ Selesai & RS Siloam & Kunjungan / Detailing \\
\hline Sabtu & $26 / 09 / 2020$ & $08.00 \mathrm{~s} / \mathrm{d} 12.00$ & Kantor & Laporan Mingguan \\
\hline Senin & $28 / 09 / 2020$ & $08.00 \mathrm{~s} / \mathrm{d}$ Selesai & Kantor & Pembuatan ReKun \\
\hline Selasa & $29 / 09 / 2020$ & $08.00 \mathrm{~s} / \mathrm{d}$ Selesai & RS Radjak & Kunjungan / Detailing \\
\hline Rabu & $30 / 09 / 2020$ & $08.00 \mathrm{~s} / \mathrm{d}$ Selesai & Kantor & Closing Bulanan \\
\hline Kamis & $01 / 10 / 2020$ & $08.00 \mathrm{~s} / \mathrm{d}$ Selesai & Kantor & Laporan awal Bulan \\
\hline Jum'at & $02 / 10 / 2020$ & $08.00 \mathrm{~s} / \mathrm{d}$ Selesai & Kantor & Laporan awal Bulan \\
\hline Sabtu & $03 / 10 / 2020$ & $08.00 \mathrm{~s} / \mathrm{d} 12.00$ & Kantor & Laporan Mingguan \\
\hline Senin & $05 / 10 / 2020$ & $08.00 \mathrm{~s} / \mathrm{d}$ Selesai & Kantor & Pembuatan ReKun \\
\hline Selasa & $06 / 10 / 2020$ & $08.00 \mathrm{~s} / \mathrm{d}$ Selesai & RS Asri & Kunjungan / Detailing \\
\hline Rabu & $07 / 10 / 2020$ & $08.00 \mathrm{~s} / \mathrm{d}$ Selesai & RS Ramahadi & Kunjungan / Detailing \\
\hline Kamis & $08 / 10 / 2020$ & $08.00 \mathrm{~s} / \mathrm{d}$ Selesai & RS Siloam & Kunjungan / Detailing \\
\hline Jum'at & $09 / 10 / 2020$ & $08.00 \mathrm{~s} / \mathrm{d}$ Selesai & RS Asri & Kunjungan / Detailing \\
\hline Sabtu & $10 / 10 / 2020$ & $08.00 \mathrm{~s} / \mathrm{d} 12.00$ & Kantor & Laporan Mingguan \\
\hline
\end{tabular}




\section{KESIMPULAN}

Berdasarkan hasil data yang diteliti oleh penulis mengenai Strategi Bauran Pemasaran (Marketing Mix) dalam meningkatkan Omzet Penjualan Di PT. Sanbe Divisi Infus Area Purwakarta. Maka penulis dapat mengambil kesimpulan bahwa Strategi Bauran Pemasaran (Marketing Mix) dalam meningkatkan Omzet Penjualan Di PT. Sanbe Divisi Infus Area Purwakarta tidak terlepas dari konsep Bauran Pemasaran 4P yaitu :

a. Product (Produk)

Dimana PT. Sanbe Divisi infus Area Purwakarta unggul dalam kemasan karena menggunakan kemasan softbag

b. Price (Harga)

Harga produk infusan PT. Sanbe Divisi Infus Area Purwakarta mampu mengikuti trend market sehingga mampu bersaing di area coverage

c. Place (Distribusi)

Responsif distribusi dari PT. Sanbe Divisi Infus Area Purwakarta terhadap demand/permintaan Rumah Sakit sangat stabil, karena selalu memenuhi demand/permintaan dari Rumah Sakit tersebut. Sehingga PT. Sanbe divisi Infus Area Purwakarta menjadi Market Leader di Area covarage

d. Promotion (Promosi)

Peran dari Medical Representative dari PT. Sanbe Divisi Infus Area Purwakarta sangat vital karena menjadi ujung tombak perusahaan sekaligus duta perusahaan. Melalui Personal Selling terhadap Rumah Sakit area Purwakarta secara maintenance, sehingga omzet/penjualan dari produk infusan PT. Sanbe Divisi Infus Area Purwakarta selalu stabil bahkan cenderung meningkat dari setiap bulannya.

\section{Artikel Jurnal}

\section{DAFTAR PUSTAKA}

Hartono, Hendry; Hutomo, Karyana; Mayangsari, Marshelia. Pengaruh Strategi Pemasaran Terhadap Peningkatan Penjualan Pada Perusahaan" Dengan Menetapkan Alumni Dan Mahasiswa Universitas Bina Nusantara Sebagai Objek Penelitian. Binus Business Review, 2012, 3.2.

Kusnawan, Galih; Wijoyo, Purwohadi. Pengaruh Strategi Bauran Pemasaran (Marketing Mix) Terhadap Efektivitas Volume Penjualan Sayuran Hidroponik. Agricultural Socio-Economics Journal, 2008, 8.2.

Nasution, Muhammad Irfan; Prayogi, Muhammad Andi; Nasution, Satria Mirsya Affandy. Analisis Pengaruh Bauran Pemasaran Terhadap Volume Penjualan. Jurnal Riset Sains Manajemen, 2017, 1.1. 
Ngafifi, Muhamad. Kemajuan Teknologi Dan Pola Hidup Manusia Dalam Perspektif Sosial Budaya. Jurnal Pembangunan Pendidikan: Fondasi Dan Aplikasi, 2014, 2.1. Rachmawati, Rina. Peranan Bauran Pemasaran (Marketing Mix) Terhadap Peningkatan Penjualan (Sebuah Kajian Terhadap Bisnis Restoran). Jurnal Kompetensi Teknik, 2011, 2.2.

Suddin, Andi Faisal. Pengaruh Bauran Pemasaran Terhadap Volume Penjualan Produk Ayam Pedaging Di Kota Makassar. Jurnal Ilmu Dan Industri Peternakan, 2013, 1.1.Nasution, Muhammad Irfan; Prayogi, Muhammad Andi; Nasution, Satria Mirsya Affandy. Analisis Pengaruh Bauran Pemasaran Terhadap Volume Penjualan. Jurnal Riset Sains Manajemen, 2017, 1.1.

Tambajong, Geraldy. Bauran Pemasaran Pengaruhnya Terhadap Penjualan Sepeda Motor Yamaha Di PT. Sarana Niaga Megah Kerta Manado. Jurnal EMBA: Jurnal Riset Ekonomi, Manajemen, Bisnis Dan Akuntansi, 2013, 1.3. 